Letros. Lima, Univ. Son Marcos. 90: 71-92. 1986

\title{
La investigación musical en América del Sur
}

RAUL R. ROMERO

El objeto del presente trabajo es el de presentar una breve y condensada historia de la investigación musical en América del Sur, en lo que concierne especificamente a las expresiones tradicionales. Desde comienzos de siglo, empezaron a aparecer los primeros estudios sistemáticos sobre música tradicional en los diferentes países sudamericanos. En la década del treinta ya era evidente el auge de la producción etnomusicológica intensificado por la prolificidad de Carlos Vega y la aparición de una revista que centralizó muchos esfuerzos aislados, el Boletín Latinoamericano de Música.

Hasta la década del sesenta estos interitos se caracterizaron por tener una perspectiva común, en teoría $y_{n}$ método, hacia el estudio de la música tradicional. Esta homogeneidad confirma la idea de que estos años (1930-1960) pueden ser concebidos como un ciclo en que puntos de vista "tradicjonales" prevalecieron. En la década del sesenta la aparición de modernas perspectivas determina el fin de esta prevalecencia. Desde ese momento, la etnomusicología "tradicional" ha co-existido con estas nuevas corrientes.

En este artículo, el énfasis es puesto en el período que he denominado "tradicional", aunque habrán constantes referencias a prácticas etnomusicológicas previas y recientes.

Algunas precisiones deben ser establecidas, sin embargo. En primer lugar, excluyo de esta evaluación el caso del Brasil por razones históricas y culturales, limitándome a Sudamérica hispana. En segundo lugar, debe recordarse que este trabajo tratará sobre la etnomusicología sudamericana y no sobre la etnomusicologfa en América del Sur. En otras palabras, se excluyen las contribuciones de investigadores foráneos para enfatizar el desarrollo de los estudiosos nativos, y sólo en algunos casos, de aquéllos investigadores europeos que han hecho de algún país de Amética del Sur su nuevo hogar. 
Las razones para esta exclusión es evidente. Los trabajos de aquéllos etnomusicólogos foráneos que han venido a esta parte de! mundo sólo por un período limitado de tiempo, mientras que han contribuido al conocimiento global de la música tradicional sudamericana, son una consecuencia del estado académico de sus respectivos países de origen. Por lo tanto, no representan adecuadamente las corrientes autóctonas seguidas por los investigadores sudamericanos.

\section{Predecesores en el periodo colonial}

Junto con los humanistas del renacimiento y los racionalistas del siglo XVIII como Jean-Jacques Rousseau (Nettl 1964: 13), los cronistas españoles del período temprano colonial, pueden ser también considerados como unos de los primeros predecesores de la etnomusicología. Sus escritos cubrieron una amplia variedad de aspectos acerca de la vida en el imperio incaico, siendo la música un campo que mereciera un reconocimiento especial como una importante expresión cultural de la civilización inca. Guamán Poma de Ayala, por ejemplo, dedicó un considerable número de páginas de su vasta obra a la descripción de actividades musicales (La Nueva Cronica y Buen Gobierno, 1613). Muchos de sus conocidos dibujos acerca de la vida cotidiana pre-colombina muestran instrumentos musicales y sus ejecutantes. Además de Poma de Ayala, otros cronistas españoles como Pedro Cieza de León (EI Señorio de los Incas, 1553), Bernabé Cobo (Historia del Nuevo Mundo, 1653) y Garcilaso de la Vega (Comentario Reales de los Incas, 1609), ofrecieron interesantes descripciones de una variedad dejaspectos musicales que nos han sido aún sistemáticamente examinados. Con la excepción del intento de Stevenson (1960) por resumir lá visión que los cronistás tenían de la música, no existe otro esfuerzo por evaluar sus méritos musicales. En la mayor parte de los casos, las referencias etno-históricas han sido presentadas por los etnomusicólogos sólo para confirmar los orígenes prehispánicos de algún fenómeno en particular.

Sus más valiosas y sugerentes referencias musicales pueden ser agrupadas en las siguientes áreas:

\section{1.-Diversidad Regional y Etnica.}

No obstante el mundo andino ha sido visto a menudo en la literatura etnomusicológica como un todo musical homogéneo, los cronistas enfatizaron las diferencias musicales entre las diversas regiones y grupos étnicos. Bernabé Cobo (1956: 270) fue uno de los que captaron este fenómeno con más claridad:

...Cada provincia de las de todo el imperio de los Incas "tenía su manera de bailar, los cuales bailes nunca trocaban; aunque 
ahora cualquier nación, en. las fiestas de la iglesia, imita y contrahace los bailes de las otras provincias.

Guamán Poma de Ayala (1956: 242) çorrobora la impresión de Cobo, notando el factor étnico en este proceso:

De este modo, las cưatro partes del Tauantinsuyo tenían sus respectivos versos y sus Taquíes. Los Quichuas, Aymarays, $\mathrm{Co}$ llas, Soras, y algunos pueblos de los Condes, tenían sus versos especiales.

Sus observaciones acerca de la riqueza y variedad de los estilos musicales crecen en importancia considerando que la sociedad andina contemporánea presenta iguales características de diferenciación musical. La diversidad musical, por to tanto, es un rasgo cultural que tiene antecedentes pre-colombinos, una realidad que debería tenerse en consideración en cualquier estudio actual de la música andina.

\section{2.-Música y estructura social.}

La existencia de una música "folklórica" en oposición a una música "oficial" ha sido claramente documentada por los cronistas. Como ha sido dicho líneas arriba, la música andina ha sido considerada como un todo, sin tener en consideración que en una sociedad estratificada la música tiende a reflejar la diferenciación social y cultural. En tiempos pre-colombinos ciertos tipos de música estaban asociados con la nobleza y estaban reservados para rituales muy especiales. Por lo tanto, era música nol apta paracel consumo popular y estaba reservada para una élite. "Probablemente, esto explica su desaparición luego de la conquista española y la desintegración de la jetarquía inca, mientras que la música popular siguió vigente (1). Cobo (1956: 271) describe un caso en que sólo los miembros de la jerarquía podían participar:

El baile propio de los Incas se dice GUAYYAYA; no entraban en él en tiempo de su gentilidad sino solos los del linaje de los Incas de sangre real, y llevaban delante el estandarte o guión del Rey, con el champi, que eran las insignias reales. Bailábanlo al son de un atambor grande, que llevaba sobre las espaldas un indio plebeyo o villano, y lo tocaba una mujer... Algunas veces en fiestas muy graves, entraba el mismo Inca en estos bailes.

Cobo también mencionó otra danza en que el inca mismo danzaba con mujeres con la música de un "arauis" (1956: 271), y Poma

(1) Idea sugerida por Robert Stevenson (1960: 145). 
de Ayala (1956: 235) describe el "uaricza araui", un canto ejecutado por el Inca y un coro de jóvenes doncellas.

Los cantares históricos son también parte de esta tradición. Cieza de León explica con cierto detalle la función de estos cantares que asemejan a los romances y villancicos españoles. De acuerdo con Cieza de León estos cantares eran recuentos históricos de glorias pasadas, de los logros de los emperadores incas. Unos pocos elegidos eran seleccionados para memorizar estas canciones que contenían en sus textos muchos años de historia. Eran interpretados sólo en ocasiones muy especiales y siempre en presencia de la nobleza y el Inca (Cieza de León 1967: 30-32).

Stevenson ha mencionado el caso de las muy apreciadas conchas marinas, utilizadas en el imperio incaico como instrumentos musicales (1960: 24-25). Las conchas eran usadas para propósitos rituales relacionados a las "huacas" o deidades incas, y eran además un símbolo de poder y prestigio. Las autoridades eran enterradas con estas conchas como signo de su status. Estos instrumentos eran adquiridos a través del comercio e intercambiados por otros bienes de valor como ornamentos de oro y plata. Por lo tanto, no era considerado un instrumento popular, y siempre permaneció, como dice Stevenson, como un símbolo aristocrático.

Estos pocos ejemplos corroboran la existencia de una música popular opuesta a una actividad musical restringida de y para los altos niveles de la sociedad inca. Teniendo en cuenta que el imperio fue una estructura estratificada, no debe sorprender que la música reflejara esta realidad social.

\section{3.-Géneros Müsicalee.uccinelli Converso»}

La diversidad regional y étnica tenía que ser acompañada por un proceso de diferenciación musical que resultara en una rica variedad de danzas y canciones. Cobo (1956: 270-271) expresó sus emociones frente a este mosaico:

...y así es muy de ver las muchas y diversas danzas que sacan en la procesión del Santísimo Sacramento y en otras fiesvincia del Collao a la procesión una vez en un pueblo de la procuarenta danzas déstocesión de Corpus Christi, conté en ella en el traje, cantar y mas, diferentes unas de otras que imitaban yas eran propias

Lamentablemente, las caracterizaciones que sobre la música y las danzas elaboraron los cronistas fueron hechas sobre la base de los textos de las canciones, dejando de lado los rasgos propiamente musicales. Por esta razón la mayor parte de sus referencias pertenecen 
al dominio de los trazos literarios y su información no permite un adecuado entendimiento de las piezas descritas en términos de su estructura musical. En general, las referencias a géneros musicales, en consecuencia, tienden a ser meramente nominativas o definidas en relación a su "carácter". Poma de Ayala, por ejemplo, menciona varios géneros musicales indicando su carácter general y ofreciendo una transcripción de sus textos. Entre ellos, el "haraui" (una nostálgica canción de amor), la "cachiua" (canción alegre), y la "uanca" (también una canción de àmor), aparecen como las más importantes (Poma de Ayala 1956: 233-235). Bernabé Cobo corrobora las referencias de Poma de Ayala (Poma de Ayala 1956: 233) en relación al "haylli" (Cobo 1956: 271), una canción de la cosecha que de acuerdo con Poma de Ayala era cantada por mujeres y acompañada por "pingollos" o flautas ejecutadas por hombres.

Diccionarios coloniales como el Vocabulario de la Lengua General de Todo el Perú llamada Ingua Qquichua (1608) de Diego González Holguín y el Vocabulario de la Lengua Aymara de Ludovico Bertonio (1612) contienen también valiosa información acerca de los géneros musicales. Tomando en consideración que el término "taqui" se refería igualmente a la canción y a la danza (Holguín 1952: 194), Roel ha utilizado estas fuentes coloniales en su reconstrucción del "wayno" (Roel 1959).

4.-Instrumentos Musicales y Aspectos de la ejecución musical.

Las referencias y descripciones de instrumentos musicales son abundantes en los cronistas, y son una indicación del amplio y varia-

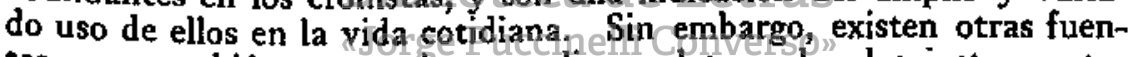
tes que también proporcionan valiosos datos sobre los instrumentos musicales pre-hispánicos. Estos son, entre otros, los restos arqueológicos de los propios instrumentos y los diseños contenidos en cerámicas pre-colombinas y textiles. Los cronistas, sin embargo, confirman la existencia de numerosos tipos de tambores, idiófonos, flautas y trompetas en el imperio inca, así como la inexistencia de instrumentos de cuerda. También podemos encontrar información acerca de la función de algunos instrumentos, como el ya menciando caso de las conchas marinas, y las "queppas" (trompetas), esta última usada en ocasiones solemnes asociadas con actos bélicos. Stevenson (1960) y Jiménez Borja (1951) han compilado numerosas referencias de los cronistas acerca de instrumentos musicales en estudios que deben ser guías básicas para el lector interesado en esta rama.

Por otro lado, las referencias a aspectos de la ejecución musical son escasas, pero constituyen las únicas descripciones técnicas de prácticas específicas pre-colombinas. Unas de las más detalladas descripciones de ejecuciones musicales es la versión de Garcilaso de la Vega acerca de los grupos de flauta de pan (1959: 201): 
Guando un indio tocaba un cañuto, respondía el otro en consonancia de quinta o de otra cualquiera, y luego el otro en otra conisonancia y el otro en otra, unas veces subiendo a los puntos altos y otras bajando a los bajos, siempre en compás.

En relación a la escala musical, Garcilaso notó la presencia uso de largos intérvalos en lugar de pequeños (1959: 201):

No supieron echar glosa con puntos disminuidos; todos eran enteros de un compás.

Poma de Ayala menciona el acompañamiento musical que ejecutan los "pingollos" y "quena-quena" en varias danzas y canciones (1956: 233), y también ha resaltado dos casos de canto antifonal entre hombres y mujeres. El primero de éstos, el "uaricza araui", era cantado por el Inca con la colaboración de una llama (Poma de Ayala 1956: 236). El canto imitaba el suave gemido del animal, y era repetido una y otra vez hasta aproximarse al sonido agudo emitido por la llama. El canto era

De acuerdo con Vega (1932: 350). Garcilaso pudo haber estado tratando de describir la escala pentatónica anhemitonal, es decir, sin semitonos, supuestamente la de mayor uso en el imperio incai$\mathrm{co}$, o al menos, una de las más recurrentes entre otras existentes.

..entonạdo simultáneamente por el Inca, que decía "Yn" varias veces, conservando un ritmo y tono apropiados, interrumpido frecuentemente por coplas que contestaban siempre las $\mathrm{CO}$ YAS y NUSDAS, - quienes primero entonaban en voz alta, para ir bajando pocera pocochasta obteners un tono suave que distinguía a la UARICZA y al ARAUI.

El segundo caso de canto antifonal era el denominado "saynata", de temática irónica en la cual un hombre respondía a un coro de mujeres (Poma de Ayala 1956: 242).

No obstante estas breves descripciones de técnicas musicales, demuestran el interés de los cronistas en la música en si misma, ellos no dejaron en sus obras ninguna transcripción musical. El primer intento por documentar en forma escrita la música popular en América del Sur, ocurriría más tarde en el período colonial.

El Obispo Baltazar Martínez y Compañón incluyó veinte páginas de música en su obra de nueve volúmenes acerca de la vida y naturaleza de Trujillo, la ciudad en la que él desempeñó su cargo. Su trabajo, escrito en la segunda mitad del siglo XVIII, pretendía ser una etnografía general de la región, describiendo varios aspectos de la vida provincial de Trujillo, tales como las costumbres y comportamiento (vol. I), la flora y la fauna (vol. III al VIII), la historia (vol. IX). La música, ocupó las páginas 176-194 del volumen II y 
consistía en 17 canciones y 3 danzas instrimentales recopiladàs cerca de Trujillo (Vega 1978: 12).

Entre otras contribuciones en esta misma línea, está la colección de Gregorio de Zuola, que presenta 17 piezas de música de origen anónimo, como parte de su enciclopedia de cerca de 500 páginas escrita en los últimos años del siglo XVII. Sin embargo, está colección, así como otras de menor importancia, presentaban recopilaciones de marcado origen hispano-europeo, siendo mínimos los rasgos indígenas (Stevenson 1960: 151-154).

Los cronistas españoles tempranos fueron los responsables de los primeros intentos por documentar y comunicar la música indígena de sudamérica a una audiencia foránea. Los cronistas fueron los primeros etnomusicólogos, no sólo porque fueron los primeros escritores en atreverse a poner aténción a la música, sino porque al tratarla la consideraron como una parte integral del mundo social y cultural que ellos intentaban describir.

Al concluir la dominación colonial en América del Sur, las nuevas repúblicas tuvieron que reorganizar sus estructuras económicas y políticas: El siglo XIX es un período en que hay poca actividad en lo que se refiere a la investigación musical. La recolección de melodías autóctonas se convierte en la actividad dominante, seguida por unos pocos. compositores y músicos que estaban iniciando al exploración de un mundo diferente, anticipando los comienzos del academicismo moderno en las primeras décadas del siglo $\mathrm{XX}$.

\section{Los Comienzos del Academicismo}

La investigación musical en el siglo XIX consistió principalmente en la colección de melodías tradicionales. La noción de que las melodías autóctonas tenían que ser preservadas y presentadas al público urbano, arregladas de acuerdo a las reglas del "arte", estaba muy difundida en esta época. Un ejemplo de esta práctica es la colección de Marcos Jiménez de la Espada "Colección de Cantos y Bailes Indios. de Yaravíes Quiteños" (1881), que incluía 20 yaravíes y cuatro" danzas, las mayoría de ellas arregladas para el piano. "Otras colecciones Je importancia fueron la de.V.R. Lynch ("La Provincia de Buenos Aires hasta la .Definición de la Cuestión Capital de la República") en 1883, y la de Daniel Alomía Robles, que recolectó intensamente melodías andinas durante los últimos años del siglo XIX y comienzos del siglo XX. El acumuló más de 1,000 melodías indígenas transcritas y enriqueció sus anotaciones con comentarios acerca de las ocasiones en que aquéllas melodías se manifestaban." Esta colección constítuye una de las más valiosas contribuciones a la preservación del patrimonio musical andino, pero lamentablemente permanece inédita.

La actitud de arreglar las melodías tradicionales para satisfacer las demandas estéticas occidentales, fue también la principal motivación detras del Album Sudamericano (1870) de Claudio Rebagliati. 
Rebagliati, nacido en Italia aunque luego residió en el Perú, incluyó en su colección 22 canciones, andinas y criollas, y las arregló para el piano. Consciente de su intento para adaptar las melodías recopiladas por él mismo al gusto europeo, escribió en el prefacio de su obra (Raygada 1964: 64):

Esta colección consta de aires populares inéditos y anónimos, conocidos en Sud América sólo por tradición y por lo mismo ejecutados de diversos modos y siempre incorrectamente. $\mathrm{Mi}$ intención ha sido sujetarlas a las reglas del Arte cuidando al mismo tiempo de no hacerles perder en nada el colorido que les es peculiar...

La justificación de Rebagliati ejemplifica la mentalidad de los coleccionistas de música tradicional del siglo XIX. Mientras que el acto por recopilar reflejaba un importante interés en la música tradicional, prejuicios coloniales y perspectivas etnocéntricas aún prevalecían. Las melodías indígenas no podían ser presentadas tal como eran, quizás porque ellas representaban el primitivismo de la población rural o los pobres de la ciudad. Arregladas para el piano - el instrumento característico de la música europea - o para una pequeña orquesta, asumirían un nivel aceptable a fin de justificar su preservación.

No obstante el etnocentrismo manifestado en rstos arreglos, el interés mostrado en recopilar y transcribir las melodías tradicionales para su publicación, revela que la música autóctona estaba comenzando a ser considerada un objete de setia a tención. S

Las primeras señales pque indicaban un serio interés en estudiar sistemáticamente la música tradicional, aparecieron en el Cuzco a principios del siglo XX. Estos intentos estuvieron dedicados a la discusión sobre el uso de la escala pentatónica en la música andina. José Castro, un pianista y compositor cuzqueño, fue el primero en llamar la atención sobre el uso de esta escala con una monografía titulada "Sistema Pentafónico en la Música Indígena Pre-Colonial del Perú" (1898). Castro, de acuerdo a su propia confesión, se dio cuenta del uso de la pentatonía mientras tocaba las teclas negras del piano. El analizó las escalas pentatónicas usadas en 24 canciones obtenidas de diversos recopiladores cuzqueños y elaboró sus características estructurales y diferencias con la escala diatónica occidental. Años más tarde, Leandro Alviña, un estudiante en la Universidad del Cuzco y también compositor por propio derecho, escribió una tesis sobre la "música inca" (1908), centrándose en el uso de la pentatonía (2).

(2) La tesis de Alviña no se limitó a este problema. Intento además reconstruir la historia de la música peruana a trovés de etapas, dividiendo su estudio en: la música pre-colombina; etapa de la conquista; la independencia; y el período republicano. 
Simultáneamente, Daniel Alomía Robles, había notado la importancia de la pentatonía en la música andina como resultado de sus viajes al campo y recopilaciones. Sus pensamientos en esta materia, aunque nunca fueron escritos y publicados, fueron resumidos y presentados por Alberto Villalba Muñoz en una conocida conferencia en la Universidad de San Marcos en Lima (Villalba, 1910).

La discusión sobre el uso de la pentatonía, fue la primera manifestación de un creciente interés en el análisis de estructuras musicales que tiempo mas tarde iba a ser continuado por diversos autores (3).

No obstante fue el Cuzco el centro de la discusión y Alviña el primer estudiante universitario que demostró que la música podía ser un objeto de investigación académica, no fue aquí donde se formó un núcleo de actividad etnomusicológica. Habría que esperar hasta la década del treinta para que los estudios sistemáticos empezaran a difundirse por toda América del Sur. El centro de actividad más importante se crearía alrededor de la figura de Carlos Vega en Argentina. Vega, un musicólogo de formación auto-didacta, se integró en 1926 al Museo de Ciencias Naturales donde se creó un Gabinete de Musicología Indígena, y en 1931 fundó y dirigí el Instituto de Musicología del Ministerio de Educación Bajo los auspicios de estas instituciones Vega inició un período intenso de investigaciones y publicaciones, no limitándose a la música argentina, sino incluyendo inclusive otros países de Sudamérica. Desde inicios de la década del treinta Vega viajó a Chile, Perú, Bolivia y Paraguay, recopilando cientos de melodías y datos para sus futuros trabajos. Desde entonces y hasta su muerte en 1966, Vegae publicó constantemente, congregó a talentosos discípulos alrededor suyo, y se convirtió en el autor más influyente y creativo entre sus colegas sudamericanos.

En la década del treinta Vega anticipó algunos de sus proyectos futuros a través de numerosos artículos en La Prensa de Buenos Aires. En esta tribuna, Vega escribió sobre una variedad de canciones y danzas argentinas, revelando un interés especial en los problemas de los orígenes y aplicando la teoría de las supervivencias de Tylor al folklore latinoamericano (4). La primera contribución mayor de Vega en là década fue "La Música de un Códice Colonial del siglo XVII" (1931), en el que present 6 las transcripciones del manuscrito de De Zuola, una colección colonial de música popular de la época. Sin- embargo, la obra propiamente etnomusicológica de Carlos Vega

(3) El uso de la pentatonlo ha sido un tópico favorito de dlscusión en sudomérico. Después de Costro y Alviño, muchos investigadores de renombre escribieron sobre este ospecto. Ver por ejemplo a Corlos Vego (1932), Volcórcel (1932), Sas (1938) y Aretz (1952b). La clasificoción de los D'Horcourt acerco de los modos pentotónicos ho sido uno de las hipótesis mas influyentes sobre este problema (1925).

(4) Algunos oños mós tarde, en Danzos y Canciones Argentinas (1936), Vega sintetizarío sus pensomientos en esta materia. 
fue inaugurada por dos ponencias que él presentó en el XXV Congreso Internacional de Americanistas en La Plata en 1932. El primero de ellos, "La Flauta de Pan Andina", era una monografía en que Vega dedicó la mayor parte de su análisis a demostrar el origen Polinesio del instrumento. Su interpretación estaba basada en los postulados de la Escuela Antropológica Alemana de los círculos culturales ("Kulturkreis") que Vega había aceptado desde su incorporación .al Museo de Ciencias Naturales (5). En su segunda ponencia (Vega 1932b) especuló acerca del uso de la pentatonía en la música andina y se pronunció contrario a la idea de su uso generalizado en tiempos pre-colombinos, asegurando en cambio, que otros sistemas tonales también eran empleados por los antiguos peruanos.

Lejos del círculo de Carlos Vega, la década del treinta fue testiga del surgimiento de la actividad etnomusicológica en otros países. La coincidencia de iniciativas individuales en Chile, Ecuador, Perú y Colombia, sugiere un campo común favorable a la investigación. La aparición de amplias visiones panorámicas caracteriza mucha de la producción relevante de aquéllos años. "La Música en el Ecuador", de Segundo Luis Moreno (1930), fue el primer intento por escribir un recuento histórico de la música ecuatoriana, y pretendía introducir al lector a la variedad de tradiciones musicales de ese país. Tareas y objetivos similares persiguieron asimismo Carlos Raygada en el Perú (1936), J. I. Pardomo Escobar en Colombia (1938) y Eugenio Pereira Salas en Chile (1941) (6).

La perspectiva holística de estos trabajos explica la inclusión simultánea de las tradiciones académicas y orales como partes integrales de la herencia lousicatenacional. Aaldemás, la amplitud de ellos era una consecuencia de la escasez de estudios previos, lo que obligaba a estos investigadores a escribir tratados globales y generales como un modo de cubrir todos los materiales existentes que de otro modo hubieran permanecido ignorados.

En esta década aparecieron, asimismo, trabajos de contenido más específico. Los artículos de Carlos Isamitt sobre instrumentos musicales araucanos iniciaron el estudio organológico en Chile (1935, 1937. 1938). En el Perú, el compositor belga-peruano Andrés Sas publicó una serie de artículos sobre la música peruana tradicional. Su "Ensayo sobre la música Nazca" (1938), proporcionó importantes evidencias en favor de la hipótesis de que la pentatonía no era la única escala utilizada en tiempos pre-hispánicos. En artículos previos, Sas había

(5) Según Pola Suárez Urtubey, el primer contacto de Vega con la antropologia, ocurrió cuando él se asoció al Museo de Ciencias Naturales. Ver el prólogo a la Revista del Instituto de Investigación Musicológica Carlos Vega $1(1): 5$.

(6) No obstante que el trabajo de Pereira Salas aparece en 1941, es decir, no estrictamente en la década del treinta, pertenece estilisticamente al grupo mencionado. La división en décadas preseniada en esta sección debe ser entendida como flexible $y$ aproximada. 
analizado los patrones armónicos andinos (1935) y la formación histórica del folklore peruano (1936). También en el Perú, Teodoro Valcárcel, un importante compositor relacionado a las corrientes nacionalistas del tiempo, intentó iniciar una investigación seria e institucional a través del departamento de folklore del Conservatorio $\mathrm{Na}$ cional de Música. Sin embargo, su ambicioso proyecto que incluía la recopilación, clasificación y análisis de la música tradicional peruana, nunca pudo ser desarrollado (Valcárcel, 1936).

Imprescindible para el desarrollo de la investigación en la década del treinta, fue la aparición del Boletín Latiro Americano de Música en 1935, fundado y dirigido por el musicólogo Alemán-Uruguayo Francisco Curt Lange. Bajo los auspicios del Instituto de Estudios Superiores de Montevideo, Lange cré el Boletín como una respuesta a su esperanza en el desarrollo autónomo de la música americana, a pesar del predominio de valores europeos en las esferas culturales de las élites sudamericanas. El Boletín sirvió a este ideal convirtiéndose en la vitrina de los trabajos y estudios de los investigadores de la música americana tradicional o académica. La publicación y difusión de estos trabajos era la primera etapa para el desarrollo del "americanismo musical", como el mismo Lange llamaba a este movimiento (Curt Lange, 1935, 1936).

En este contexto, la investigación de la música tradicional cumplía un rol básico: el de mostrar a la vasta comunidad interamericana, a través del análisis sistemático, los elementos de la música autóctona que podría setvir como las raíces de un desarrollo autónomo de la música académica americana.

Muchas de las más valiosas contribuciones a la etnomusicología sudamericana, fueron publicadas en este Boletín. Entre ellas, la serie de Isamitt sobre organología chilena (1935;11937; 1938), la serie de Sas sobre música tradicional peruana (1935; 1936; 1938) y las visiones panorámicas de Raygada (1936) y Pardomo Escobar (1938), aparecen como las más representativas.

El Boletín, por lo tanto, coincidió con el auge de la investigación musical en estos años y sirvió como un vehículo para su difusión a un nivel inter-americano. También orientó una actividad de investigación individualista hacia objetivos comunes.

Las siguientes dos décadas fueron de maduración de corrientes previas. El núcleo de Carlos Vega en Argentina, siguió jugando un rol central por sus talentosas publicaciones y el trabajo de sus discípulos, quienes en la década del cuarenta estaban ya dispuestos a coninuar el legado de Vega. Mientras que en la década anterior Vega había investigado y escrito sobre una variedad de temas, es en la década siguiente que él estructura definitivamente sus principales teorías y métodos. Su propuesta para el análisis de la estructura de la frase musical (1941); su división de sudamérica en áreas musicales que denominó "cancioneros" (1944); y su tratado de organología en la que él introdujo por vez primera el sistema de clasificación Sachs- 
Hornbostel (1946); pueden ser consideradas como sus más importantes contribuciones en este período.

Igualmente importante en Vega fue su gran capacidad para formar discípulos. Isabel Aretz, su más prominente y prolífica estudiante, continuó muchas de las líneas de investigación de su maestro. En su primer trabajo, Música Tradicional Argentina: Tucumán, (1946), Aretz presentó una visión general de la música tradicional de Tucumán, tanto en el pasado como en el presente, y en El Folklore Musical Argentino (1952) un panorama global de canciones y danzas argentinas. En estas dos importantes contribuciones, Aretz siguió las teorías de Vega, citando y aplicando su método para el análisis estructural de la frase musical llamada "fraseología", así como la teoría de los "cancioneros" aceptándola como el marco general de sus estudios. En la década del cincuenta, Aretz estableció su residencia en Venezuela y desde entonces dedicó la mayor parte de su producción a la música tradicional venezolana. Sus monografías sobre los "tonos de velorio" (1947), el "mare-mare" (1958), y el "polo" (1959) son ejemplos de sus investigaciones en este nuevo período.

Luis Felipe Ramón y Rivera, un musicólogo que se relacionó con Vega y sus teorías durante el tiempo que vivió en Argentina, ha sido una figura central en la etnomusicología venezolana. Sus monografías sobre la polifonía popular (1949) y los cantos de trabajo (1955), son ejemplos destacables de su trabajo. Su libro sobre el "joropo", es un modelo de este tipo de trabajo y una de las mejores descripciones estructurales de un gênero específico sudamericano (1953). En esta monografía, Ramón y Rivera presentó una historia del "joropo", clasificó sus diversas lyariartes, dizoereferencias a los aspectos sociales que rodean su ejecucion, yanticipó el uso de su particular método de

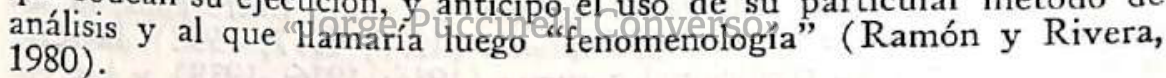
El uruguayo Lauro Ayestarán, también un cercano colaborador
de Carlos Vega, dedicó parte importante de su trabajo al estudio de la música académica de su país. Sin embargo, en 1943, Ayestarán inició una recopilación sistemática de música tradicional bajo los auspicios del departamento de musicología del Museo Nacional de Historia de Montevideo, incrementado con valiosas grabaciones su ya amplia colección (Ayestarán 1971: 19, 23). Aunque Ayestarán no escribió tratados extensos sobre música tradicional, publicó en cambio pequeños artículos sobre canciones y danzas populares en "El Día", uno de los principales periódicos del Uruguay (7).

El rol activo que Curt Lange cumplió en la reunión de esfuerzos aislados de etnomusicólogos independientes en América del Sur, llegó a su fin abruptamente en 1947 con la última edición del Boletín Latino Americano de Música (volumen VI). La falta de auspicio y apo-

(7) Estos artículos fueron publicados en un libro llamado El Folklore Musical Uruguayo. Montevideo: Arca, 1972. 
yo institucional forzó a Lange a poner fin a esta aventura americanista. Lange se estableció en Mendoza, Argentina, y bajo los auspicios de la Universidad de Cuyo, editó la Revista de Estudios Musicales de 1949 a 1955. Esta revista no logró, desafortunadamente, cumplir los mismos objetivos que el Boletín en la década del treinta. Tampoco pudo hacerlo la Revista Musical Chilena, fundada en 1945 en el departamento de música de la Universidad de Chile. Mientras que el Boletín enfatizaba el inter-americanismo y otorgaba igual espacio para todos los autores latinoamericanos, la Revista, obedeciendo a diferentes propósitos, permaneció principal pero no exclusivamente, siendo un vehículo de expresión para los investigadores chilenos.

Quizás como resultado de la ausencia del Boletín de la escena musical de sudamérica, las actividades etnomusicológicas fueron escasas entre los años 1940-1960, con la mencionada excepción del círculo de Carlos Vega. En Ecuador, Segundo Luis Moreno continuó con sus solitarios esfuerzos y publicó Música y Danzas Autóctones del Ecuador (1949), y La música de los Incas (1957), una crítica del clásico libro de los D'Harcourt sobre la música andina (D'Harcourt, 1925).

Eugenio Pereira Salas, trató temas específicos de la música tradicional chilena luego de su panorama general aparecido en 1941, con una serie de artículos en la Revista Musical Chilena (1945; 1955; 1959). Finalmente, entre las más importantes contribuciones en este período se encuentra el estudio de Arturo Jiménez Borja sobre organología pre-colombina y contemporánea en la región andina (1951).

Aquéllos treinta años (1930-1960) constituyen un ciclo en sudamérica, en el cual una perspectiva en común, en teoría y método, fue adoptada para el tratamiento de da investigación sobre música tradicional. Fue un período de pioneros auto-didactas quienes, sin contar con modelos de investigación previos o un regular auspicio institucional, exploraron por vez primera áreas que nadie había estudiado anteriormente, con los medios académicos entonces disponibles.

\section{Las Corrientes Actuales}

A partir de la década del sesenta aproximadamente, la etnomusicología tradicional sudamericana co-existiría con nuevas corrientes y perspectivas practicadas por una nueva generación de etnomusicólogos. Estos introdujeron una metodología más rigurosa y la influencia teórica de modernas escuelas antropológicas.

Entre las contribuciones más importantes de los etnomusicólogos tradicionales en estos años, están los estudios de Carlos Vega sobre los arcaismos en la música tradicional latinoamericana y sobre la mesomúsica (Vega 1965 y 1966). Sus más distinguidos seguidores, Isabel Aretz y Luis Felipe Ramón y Rivera, continuaron sus estudios en Venezuela. La obra mayor de Aretz fue un tratado sobre la organología venezolana (1967) y Ramón y Rivera escribió ensayos pano- 
rámicos sobre su país, tales como La Música Folklórica de Venezuela (1969) y La Música Afro Venezolana (1971).

Sin embargo, el esfuerzo más importante de estos dos investigadores fue la fundación del Instituto Interamericano de Etnomusicología y Folklore (INIDEF) en 1970 en Caracas. Contando con la sólida ayuda financiera del gobierno venezolano y la Organización de Estados Americanos, INIDEF, bajo la dirección de Isabel Aretz, se convirtió en el centro más dinámico de actividad etnomusicológica en la región. Desde 1971, INIDEF organizó cursos avanzados de etnomusicología para becarios de distintos países americanos, y desde 1973 inició misiones al campo periódicamente, en las cuales la recopilación de datos era su objetivo principal. Las grabaciones y materiales obtenidos están depositadas en los archivos de música folklórica del INIDEF.

Las nuevas corrientes de la etnomusicología sudamericana están plasmadas en los trabajos de los autores que empezaron a producir en la década del sesenta. En el Perú, un intento digno de resaltar es la iniciativa de Josafat Roel por fundar un departamento de etnomusicología en el Conservatorio Nacional. Bajo la guía de Roel, se elaboraron importantes monografías sobre música tradicional peruana, tales como la de Félix Villarreal Vara (El Carnaval y la Marcación del Ganado en Jesús", 1959) y Consuelo Pagaza Galdo ("El Yaraví", 1960). Roel mismo escribió "El Wayno del Cuzco" (1959), un análisis histórico y musical sobre la danza más popular en el Perú.

En Chile, la existencia de un departamento de Música en la Universidad de Chile y la de una publicación periódica, favoreció el desarrollo de la investigación y la unificación de esfuerzos. Entre aquélos relacionados a la universidad Q a la Revista Musical Chilena, María Esther Grebe se constituye como la autora más prolífica y de más sólida metodología de su generación. Las contribuciones de Grebe son muchas, abarcando desde publicaciones concernientes a la teoría y método en etnomusicología $(1972 ; 1976 ; 1981)$ a estudios específicos y con atención al contexto social de música tradicional chilena (1967; 1973; 1974a; 1974b; 1974c). Manuel Danemann y Raquel Barros también han contribuido de manera importante a la etnomusicología chilena (1960a; 1960b; 1964; 1970).

Estos trabajos muestran una clara diferencia con respecto a las perspectivas tradicionales hacia el estudio de la música tradicional en América del Sur. Desde la década del sesenta el impacto de la escuela estructural-funcionalista enfatizó la noción de interacción entre la música y el contexto cultural, e introdujo métodos y técnicas mas rigurosos en el análisis y el trabajo de campo. Unidades de análisis más específicas fueron preferidas entonces en lugar de la perspectiva holística implícita en la práctica de las visiones panorámicas antes mencionadas, y fue olvidándose poco a poco la especulación basada en dogmas evolucionistas y difusionistas. 


\section{Las Areas de Investigacion}

Es posible distinguir cinco áreas fundamentales de investigación que han sido frecuentemente enfatizadas por autores sudamericanos: (1) Ensayos panorámicos; (2) Estudios organológicos; (3) Monografías sobre géneros musicales; (4) Análisis sobre la estructura de la escala; y (5) Recopilación y transcripción de melodías tradicionales.

La elaboración de ensayos panorámicos, como hemos dicho anteriormente, fue un estilo de trabajo muy preferido por los investigadores sudamericanos desde la década del treinta. La mayor parte de estas ediciones consistía principalmente en la preșentación de las canciones y danzas más importantes de una unidad territorial -una región o un país- y la descripción de sus características musicales. La justificación para tales ediciones está relacionada a la ausencia de estudios serios sobre música tradicional antes de la década del treinta, y el deseo de recopilar y preservar todo el material posible. Casi todos los intentos en este sentido hechos en Argentina (Vega 1936 y Aretz 1946; 1952), Perú (Raygada 1936), Ecuador (Moreno 1936; 1949), Venezuela (Ramón y Rivera 1969; 1971), Colombia (Pardomo Escobar 1938) y Chile (Pereira Salas 1941), responden a estas motivaciones.

Estos ensayos panorámicos estaban limitados estrictamente a materias musicales y en algunos casos llegaban a equivaler a una lista ilustrada de las canciones y danzas existentes en un país o una región. Quedaba fuera de dichos estudios el contexto socio-cultural de la música investigada y el rol y función de los intérpretes. La visión de Aretz sobre la música tradicional argentina (1952), una de las obras más importantes en esta ărea, es un ejemplo de este estilo de trabajo. La información presentada aquí/ consiste en una breve descripción de los instrumentos musicales, seguida por una sección -más de la mitad del libro- dedicada a canciones y danzas. Breves consideraciones históricas y transcripciones musicales son of recidas como parte de una introducción a la descripción analítica de los géneros en términos de consideraciones armónicas, melódicas y rítmicas. La presentación de tales materiales no ha sido, sin embargo, siempre el mismo. Autores como Raygada (1936), por ejemplo, Pereira Salas (1941), Pardomo Escobar (1938) y Segundo Luis Moreno (1930) han incluido todas las tradiciones en sus tratados -incluyendo la música académica-, dedicando tan solo una pequeña parte a la música tradicional. No obstante, fueron los primeros estudios importantes sobre música tradicional a ser publicados en sus respectivos países.

Los estudios organológicos en América del Sur, han seguido una línea similar. El libro de Carlos Vega sobre instrumentos musicales argentinos (1946), fue el primer documento importante en ser publicado en esta área. Vega siguió un patrón que puede ser considerado representativo de este estilo de trabajo. Una especial atención 
fue asignada al sistema de clasificación de instrumentos -introduciendo el sistema Sachs-Hornbostel-; a la distribución geográfica del instrumento; a los aspectos de su construcción; técnicas de ejecución; sistemas de afinación; y a breves referencias a los estilos musicales asociados con el instrumento. La perspectiva de.Vega fue globalizante, incluyendo no sólo los instrumentos de su oriunda Argentina, sino también aquéllos que - aunque también de uso popular en el NorEste argentino- eran característicos de países andinos como Perú, Chile y Bolivia.

El énfasis de Vega en la clasificación, a la cual dedicó el primer capítulo de su libro, era un signo de la gran aceptación y predominancia del sistema Sachs-Hornbostel en sudamérica. Su uso por Vega y sus discípulos (por ejemplo Aretz 1968) se debía a la necesidad de un sistema organizado de clasificación para afrontar el estudio de una gran variedad de instrumentos. Los autores mencionados tenían en común el deseo de incluir en sus tratados a la totalidad de los instrumentos existentes en sus respectivos países, en una práctica similar a las visiones panorámicas de danzas y canciones. Una excepción a este caso fue el estudio de Jiménez Borja (1951) sobre organología peruana, que no siguío el sistema de clasificación Sachs-Hornbostel. Dicho estudio era fundamentalmente un estudio histórico de instrumentos musicales pre-colombinos basado en la lectura de cronistas y viajeros. Habían referencias constantes, sin embargo, a instrumentos contemporáneos. No obstante usó una amplia división consistente en Idiófonos, membranófonos y aerófonos (no exlstían instrumentos cordófonos en el Perú pre-colombino), no habían sud-divisiones más allá de estas teategofías. Letras

Otros estudios sobrePaspectos lorganológicos más específicos (Sas 1938; Vega 1934a; González Bravo 1937, 1938, 1949; Roel 1961), también han enfatizado los aspectos estrictamente musicales del instrumento estudiado. Quedaba fuera de la perspectiva de estos trabajos el significado simbólico y social de muchos de los instrumentos sudamericanos, que fueron puesto de lado en favor de aspectos más empíricos.

La elaboración de monografías sobre géneros musicales ha sido asimismo un tema favorito entre los etnomusicólogos sudamericanos. En esta área, el análisis musical en términos de consideraciones melódicas, armónicas y rítmicas fue enfatizado. El Joropo (1953) de Ramón y Rivera es un ejemplo descollante en este tipo de estudio, en el que el autor introduce un particular estilo de análisis llamado más tarde "fenomenología". Aretz (1959), Vega (1947), Roel (1959), Villarreal Vara (1959) y Pagaza Galdo (1960), han escrito asimismo importantes trabajos sobre géneros musicales y todos ellos han tenido en común un especial interés en los aspectos formales de la música. El carácter monográfico de estos estudios favoreció la investigación intensiva del género escogido, enfatizando la información histórica, 
la descripción coreográfica (si es necesario), pero sobre todo un exhaustivo análisis musical.

El análisis estructural de la escala musical ha sido un tema recurrente, de igual manera, aunque de manera especial en el área andina. La discusión sobre el uso de la pentatonía, que fue el tema más popular en este campo desde inicios de siglo, es la causa principal para esta abundancia. Además de los problemas históricos en debate, el estudio de la escala pentatónica andina se vio limitado a su abstracta organización estructural. Por ejemplo, la principal diferencia entre los argumentos de Castro (1898) y Alviña (1908), fue que mientras el primero afirmaba que el orden era la serie do-re-misol-la, el segundo se pronunciaba por la serie la-do-re-mi-sol, variando así el tono fundamental. Una versión más elaborada fue propuesta por Raúl y Margarita D'Harcourt (1925), quienes, basándose en sus materiales recogidos IN SITU, clasificaron la pentatonía andina en cinco modos: modo A(la-sol-mi-re-do); modo B(sol-mi-re-do-la); modo $\mathrm{C}$ (mi-re-do-la-sol); modo $\mathrm{D}$ (re-do-la-sol-mi); y modo $\mathrm{E}$ (do-la-solmi-re). Otros estudios que han ido más allá de la estricta discusión sobre la pentatonía, incluyen al de Holzmann (1968) sobre el uso de diferentes escalas musicales en la música peruana. El autor presenta ejemplos que abarcan desde tres hasta siete notas y los analiza de acuerdo a su estructura formal.

Finalmente, la actividad de recopilar y publicar transcripciones sin un estudio adjunto del material presentado ha sido muy intensa desde fines del siglo XIX. En tiempos recientes, Guzmán (1929), Holzmann (1966), y Pagaza Galdo (1967) han publicado sus colecciones con el propósito de popularizar danzas y canciones tradicionales.

Un rápido examen de estas áreas de estudio fevela un interés en la forma más que en el contenido, y también, un interés en la descripción más que en la interpretación. La relación entre música y sociedad nunca ha sido un problema de estudio y el contexto de la música investigada no ha sido adecuadamente descrito en la mayoría de los casos. Se debería recordar, sin embargo, que esta característica es compartida con otras tradiciones etnomusicológicas en otras partes del mundo. Alan Merriam (1964: 38) mencionó que la etnomusicología en Europa y en Estados Unidos, también había favorecido en el pasado los estudios descriptivos. La misma caracterización puede ser aplicada a la etnomusicología sudamericana entre los años 1930 y 1960 (8).

No es por eso casual que dos de las contribuciones más impor-

(g) Recientemente, sin emborgo, hoy signos de un interés creciente en estudior la música prestando la debida atención a su contexto socio-cultural. Grebe, por ejemplo, ha aplicado principios de la antropología cognitiva en sus estudios, en especial con referencia al problema del dualismo cultural en to vido musical de los Mapuche (1973, 1974b). 
tantes de los etnomusicólogos sudamericanos consistan en métodos de análisis formal. Los métodos de Carlos Vega ("fraseología") y de Luis Felipe Ramón y Rivera ("fenomenología") fueron una respuesta a la necesidad de un criterio científico y de técnicas originales a ser aplicadas al análisis estrictamente musical. Siendo la descripción un fin fundamental y el análisis musical una práctica común e imprescindible, los investigadores sudamericanos dirigieron sus esfuerzos creativos en esa dirección.

\section{B I B L I O G R A F I A}

ALVIÑA, Leandro

1908 La Música Incaica. Universidad del Cuzco. Tesis (Letras). ARETZ, Isabel

1946 Música Tradicional Argentina: Tucumán, Historia y Folklore. Universidad Nacional de Tucumán.

1948 "Música de los Estados Aragua y Guarico. Los Tonos de Velorio", Revista Venezolana de Folklore, Vol. 1, No. 2, pp. 47-78.

1952a El Folklore Musical Argentino. Ricordi Americana, Buenos Aires.

$1952 b$ "Músicas Pentatónicas en Sudamérica", Archivos Venezolanos de Folklore, Vol. 1, No. 2, pp. 283-309.

1958 "El Maremare como Expresión Musical y Coreográfica", Boletín del Instituto de Folklore Venezolano, Vol. 3, No. 2, pp. 45-108.

1959 "El Polo", Boletin del Instituto de Folklore, Vol. 3, No. 6, pp. 227. 273.

1967 Instrumentos Musicales de Venezuela. Universidad de Oriente, Venezuela.

AYestaran, LauroBiblioteca de Letras

1972 El Folklore Musical Uruguáayo, li ArcavEditorial, Montevideo. BERTONIO, Ludovico

1956 Vocabulario de la Lengua Aymara. Litografía Don Bosco, La Paz. CASTRO, José

1938 "Sistema Pentafónico en la Música Indigena Pre-Colonial del Perú", Boletín Latino Americano de Música, Vol. 4, pp. 835-841.

CIEZA DE LEON, Pedro

1967 El Señorio de los Incas. Instituto de Estudios Peruanos, Lima. СOBO, Bernabé

1956 Historia del Nuevo Mundo (Tomo II). Ediciones Atlas, Madrid. CURT LANGE, Francisco

1935 "Arte Musical Latino Americano, Raza y Asimilación", Boletín Latino Americano de Música, Vol. 1, pp. 13-28.

1936 "Tres Conferencias en la Universidad Mayor de Son Marcos de Lima: Americanismo Musical", Boletín Latino Americano de Música, Vol. 2, pp. 117-156.

DANNEMAN, $M$. y BARROS, R.

1960a "Los Problemas de la Investigación del Folklore Musical Chileno, Revista Musical Chilena, Vol. 14, No. 71, pp. 82-100. 
1960 b "El Guitarrón en el Deportamento de Puente Alto", Revisto Musical Chileno, Vol. 14, No. 74, pp. 7-45.

1964 "Intradueción al Estudio de lo Tonodo", Revisto Musieal Chilena, Vol. 18, No. 89, pp. 105-116.

1970 El Romoncero Chileno. Universidad de Chile, Sontiogo.

GARCILASO DE LA VEGA, El Inco

1959 Comentarios Reales de los Ineas (Tomo D). Universidod Nocional Mayor de Son Marcos, Limo.

GONZALES BRAVO, A.

1937 "Kenos, pincollos y tarkas", Boletin Latine Amerieano do Músico, Vol. 3, pp. 25-32.

1938 "Trompeto, flouto troverso, tambor y charango", Boletin Latino Americano de Músico, Vol. 4, pp. 167-175.

1949 "Clasificación de los Sicus Aymaras", Revista do Estudios Muricales, Vol. 1, pp. 92-101.

GONZALES HOLGUIN, Diego

1952 Vocabulario de la Lengua General de Todo el Perí llamoda Inguo Qquichua. Instituto de Historia, Lima.

GREBE, María Ester

1967 The Chileon Verso: A Study in Musicel Arehaism. University of Californio, Los Angeles.

1973 "El Kultrún Mapuche: Un Microcosmo Simbólico", Revisto Musical Chilena, Vol. 27, No. 123-124, pp. 3-42.

1974a "La Trifonlo Atacomeña y sus Perspectivas Inter-culturales", Reviste Musical Chileno, Vol. 28, No. 126-127, pp. 21-46.

1974b "Presencia del Dualismo en la Cultura y Músico Mopuche", Revisto Musical Chilena: Vol. 28, No. 126-127, pp. 47-79.

1974c "Lo Música Alocolufe: Acuffuración y Cambia Estilistico, Revisto Musical Chileno, Vol. 28, No i 126-127. ppe 80-111.

1976 "Objeto, Métodos y Técnicas de Investigación en Etnomusicología: Algunos Problemas Bósicos", Revista Musieal Chilena, Vol. 30, No. 133.

1981 "Antropología de la Música: Nuevas Orientaciones y Aportes Teóricos en la Investigatión Musical", Revista Musical Chileno, Vol. 35, No. 153-155, pp. 52-74.

GUAMAN POMA DE AYALA, Felipe

1956 Lo Nueva Crónica y Buen Gobierno. Ministerio de Educación, Lima. GUZMAN, Victor

1929 Cancionero Incaico. Imprento de la Universidad, Buenos Aires.

HARCOURT, Raoul et Marguerite $D^{\prime}$

1925 Lo Musique des Incos of ses Sumivances. Poul Geuthner, Paris. HOLZMANN, Rodolfo

1966 Panorama de la Músico Trodicional del Perú. Cosa Mozart, Lima.

1968 "De la Trifonía la Heptafonía en la Música Tradicional Peruana", Revista San Mareas (separota).

ISAMITT, Carlos

1935 "Un Instrumento Araucano: Lo Trutruka", Boletin Lotino Americono do Músico, Vol. 1, pp. 43-46. 
1937 "Cuatro Instrumentos Musicales Araucanos", Boletín Latino Americano de Música, Vol. 3, pp. 55-66.

1938 "Los Instrumentos Araucanos", Boletín Latino Americano de Música, Vol. 4, pp. 305-312.

JIMENEZ BORJA, Arturo

1951 "Instrumentos Musicales Peruanos", Revista del Museo Nacional, Vol. 19-20, pp. 37-80.

JIMENEZ DE LA ESPADA, Marcos

1881 Colección de Cantos y Bailes Indios de Yaravíes Quiteños. IV Congreso Anual de Americanistas, Madrid.

LYNCH, Ventura R.

1925 Cancionero Bonaerense. Imprenta de la Universidad, Buenos Aires. MERRIAM, Alan

1964 The Anthropology of Music. Northwestern University Press, Evanston. MORENO, Segundo Luis

1930 "La Música en el Ecuador", en El Ecuador en Cien Años de Independencia, Orellana J. Gonzalo, ed., Imprenta de la Escuela de Artes y Oficios, Quito.

1949 Música y Danzas Aufóctonas del Ecuador. Editorial Fray Jacobo Ricke, Quito.

1957 La Música de los Incas. Casá de Ta Gultura Ecuatoriana, Quito.

NETTL, Bruno

1964 Theory and Method is Etnomusicology. The Free Press, New York.

PAGAZA GALDO, Consuelo

1961 "El Yaravi", Folklore Americano, Vol. 8-9, No. 8-9, pp. 75-141.

1967 Cancionero Andino Sur. Casa Mozart, Lima.

PARDOMO ESCOBAR, José Ignacio.

1938 "Esbozo Histórico sobre Ga Música Colombiana", Boletin Latino Ame-

PEREIRA SALAS, Eugenio

1941 Los Origenes del Arte Musical en Chile. Universidad de Chile, Santiago.

1945 "Los Estudios Folklóricos y el Folklore Musical de Chile", Rovista Musical Chilena, Vol. 1, No. 1, pp. 4-12.

1955 "Los Villancicos Chilenos", Revista Musical Chilena, Vol. 9, No. 15. pp. $37-48$.

1959 "Consideraciones sobre el Folklore en Chile", Revista Musical Chilena, Vol. 13, No. 68, pp. 83-92.

RAMON y RIVERA, Luis Felipe

1949 "La Polifonía Popular de Venezuela", Revista del Instituto Nacional de la Tradición, Vol. 1, PP. 83-92.

1953 El Joropo: Baile Nacional de Venezuela. Ministerio de Educación, Caracas.

1955 Cantos de Trabajo del Pueblo Venezolano. Fundación Eugenio Mendoza, Caracas.

1969 La Música Folklórica de Venezuela. Universidad Central de Venezuela, Caracas. 
1971 Músice Afro-Venezolana, Universidad Centrol de Venezuela. Corocas.

1980 Fenomenología de la Etnomúsiea del Aréo Lotino Americono. Conseio Nocional de la Cultura, Caracas.

RAYGADA, Corlos

1936 "Panoromó Musical del Perú", Boletín Lotino Americano de Música, Vol. 2, pp. 169-214.

1964 "Guía Musical del Perú", Fánix, No. 14, pp. 3-95.

REBAGLIATI, Cloudio

1870 Album Sudamericano, Colección de Beilles y Cantos Populores. StabiROEL, Josafot limetno de Edoardo Sonzogno, Milán.

1959 "El Wayno del Cuzco", Folkiore Americeno, Vol. 6-7, Nos. 6-7, pp. 129.245.

1961 "Un Instrumento Musical de Paracas y Q'ero", Botatín del Conservotorio Naciontal de Músico, No. 30, pp. 18-29.

SAS, Andrés

1935 "Ensayo sobre la Música Inco", Boletín Letino Americano de Músiea, Vol. 1, pp. 71-77.

1936 "La Formación del Folklore Peruano", Boletin Lotino Americano de Músico, Vol. 2, pp. 97-103.

1938 "Ensoyo sobre la Música Nazea"/Boletin Latino Americano de Música, Vol. 4, pp. 221-223.

SIGMUND, Charles

1972 "Segundo Luis Morene (1882-1972): Ecuodor's PJonear Musicologist", STEVENSON, Robert

1960 The Music of Perú. Organización de Estodos Americonos, Woshington.

1968 Music in Aztecende lina Territory. CUniverzity, of Colifornio Press, Berkeley.

VALCARCEL, Teodoro

1932 "¿Fue Exclusivamente de 5 sonidos la Escala Musical de los Incos?". Revista del Museo Nacional, Vol. 1, No. 1, pp. 115-121.

1936 "Sintesis del Plan de Trabajo del Departamento de Folklore", Boletin Latino Americano de Música, Vol. 2, pp. 458-459.

VEGA, Corlos

1931 La Música de un Códice Colonial del Siglo XVIII. Imprenta de la Universidad, Buenos Aires.

1932a "La Flouto de Pan Andina", XXV Congreso Internocional de Americonistos, Lo Ploto.

1932b "Escalas con Semitonos en la Música de los Antiguos Peruanos", XXV Congreso Internacional de Americanistos, La Plata.

1936 Danzos y Conciones Argentinas. Ricordi, Buenos Aires.

1941 Lo Músiec Popular Argentine, Fraseologia. Imprenta de la Universidod, Buenos Aires.

1944 Panorama de la Mósico Populor Argentino. Editorial Losada, Buenos Aires. 
1946 Los Instrumentos Musicales Aborigenes y Criollos de Argentina. Ediciones Centurión, Argentina.

1960 La Ciencia del Folklore. Nova, Buenos Aires.

1965 "Una Cadencia Medieval en América", Yearbook of the Interamerican Institute for Musical Rsearch, Vol. 1, pp. 94-111.

1966 "Mesomusic", Ethnomusicology, Vol. 10, No. 1, pp. 1-17.

1978 "La Obra del Obispo Martinez Comañón", Revista del Institư̧o de Investigación Musicológica Carlos Vega, Vol. 2, No. 2, pp. 7-17.

VILLALBA MUÑOZ, Alberto

1910 Conferencia Literario Musical. E. Rosay, Lima.

VILLARREAL VARA, Félix

1957 El Wayno de Jesús. Ministerio de Educación, Lima.

1959 "El Carnaval y la Marcación de Ganado en Jesús", Folklore Americano, Vol. 6-7, No. 6-7, pp. 84-128.

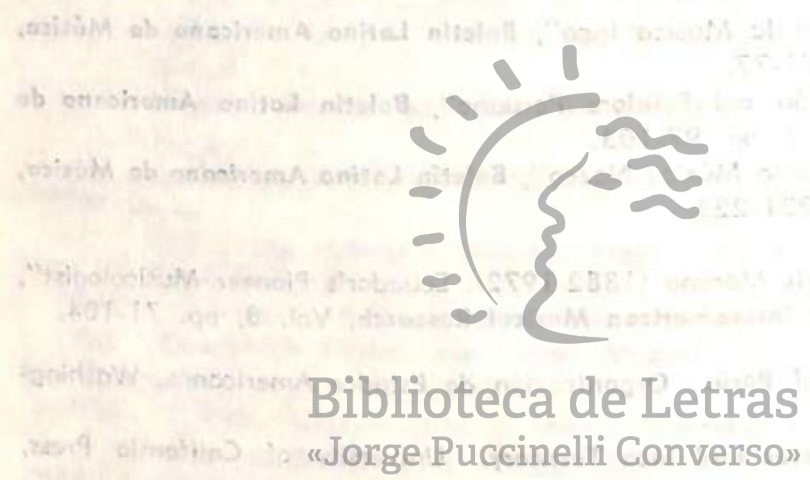

